Two cases are mentioned by Byrom Bramwell, and two probable cases by Sternberg.

As far as we can ascertain there has been no previous record of a common family predisposition to both distases. Their occurrence in parent and child may be regarded as either accidental or otherwise. The fact that the father only developed symptoms of acromegaly fourteen years after the birth of the child puts out of the question the possibility that a specific poison which produced acromegaly in him was trans. mitted to his offspring, and in her produced myxœdema.

It is more probable that there was a weakners of resistance common to both father and daughter, and that the former was unable to resist the factors producing acromegaly, while the latter succumbed to those of myxœdema.

Now as the latter disease is universally allowed to be the outcome of diminished or abolished thyroidal activity, the inference is unavoidable that if we suppose a common predisposing cause for the two conditions, we thereby admit that some disturbance of the thyroidal functions is also one of the factors in the production of acromegaly.

That this may be the case is suggested also by other facts. Most writers on the subject have referred to the many points of similarity between the two diseases. For instance, as stated by Sternberg:

"The tongue of cretins is often large, the lips puffy, thick, the nase thick and snubbed.

"The long bones of cretins often appear very thick and coarse, owing to deficiency in growth and length.

The skull of cretins is, as in acromegaly, a cranium progeneum.

"Enlarged sella turcica is present in such skulls, and the hypophysis is frequently diseased, not seldom it is enlarged.

"On the other hand, symptoms in acromegaly frequently exist which recall myxœdema. Indolence is marked, but not 80 marked as in the latter disease, and the skin in parts of the body-for example, the back of the hands-resembles myxœdematous skin closely.

"Finally, in acromegaly, the thyroid gland is seldom found normal when examined histologically."

In our own case of the father there is some loss of hair, and the face has somewhat the flushed appearance of myxœdema. The hands were thickly padded, and these symptoms were relieved by the exhibition of thyroid extract.

Finally, if we consider with some, that the overgrowth of the hypophysis is compensatory for the loss of thyroid function, we shall have less difficulty in seeing how a common predisposing condition to the two diseases may exist. We do not consider, however, that the facts we have presented warrant us in drawing more definite conclusions, but we think it desirable to place these cases on record.

$$
\text { REFERENCES }
$$

Pierre Marie and Souza-Leite, New Sydenham Society, 189r. Byrom Bramwell, Anamia and Diseases of Blood-forming Organs and Ductless Glands. Sternberg, Acromegaly, New Sydenham Society, s8g9.

\section{HUGHLINGS JACKSON AND THE CORTICAL MOTOR CENTRES IN THE LIGHT OF PHYSIOLOGICAL RESEARCH.}

Being the Second Hughlings Jackson Lecture delivered before the Neurological Society of London.

By Professor EDUARD HITZIG, M.D., Halle.

[ABSTRACT.]

AFTER some introductory remarks on the foundation of the Hughlings Jackson Lectureship and the fundamental contributions of Dr. Hughlings Jackson to the science of neurology, Profe-sor Hitzig gave an account of Dr. Jackson's earlier epochmaking work as expressed in his Study of Convulsions, which he had selected for special treatment, and then proceeded to discuss in historical sequence the stages in the development which Dr. Jackson's doctrine of the cortical motor centres had since undergone as the result of physiological investigations.

The Significance of the Cerebral Cortex.

Proceeding from the accepted facts that the grey matter of the brain had alone the power of originating movement, and that paralysis resulted either from destruction of the grey matter or of the nerve fibres leading from it to the muscles, there followed Dr. Jackson's view that the cerebral cortex, as a whole, was an organ in which motlons and sensations were represented with a definite type of localisation, and that every movement of the body was represented in every portion of the so-called motor cortex, any particular segment of the body having its maximum representation in some particular part of the cortex. Reference was then made to the evidence gained by electrical stimulation of the cortex-showing that particular parts of it were associated with particular movements, and that removal of these parts abolished the movements in question; also that Dr. Jackson's theory of the natural charging of the cortex with nerve energy and its discharge in local and general convulsions had experimental confirmation in the discovery that it was possible to charge the cortex electrically.

\section{The Existence of Special Centres in the Cerebrad} Cortex.

The lecturer next proceeded to discuss the questions whether the knowledge subsequently obtained from different sources really justified the assumption of centres in the brain cortex, and in what way such centres might be supposed to act. He pointed out that the essential point of the validity of the localisation was denied by some, for example, by Goliz and Schiff, and he brought forward the arguments which in his opinion disposed of their objections. Particularly in sttting aside Goltz's objections to stimulation experiments, based on the ground of the possible effect of the diffusion of electrical currents from the cortex to deeper-seated structures; he quoted the experiments which showed that the grey and white matter had a different kind of electrical reaction; that, as shown by Horsley and Gotch, a negative variation occurred in the pyramidal fibres of the spinal cord only when the corresponding part of the cortex was stimulated; and conversely, as shown during the last few months by Larionow, that a negative variation occurred in a restricted area of the cortex after stimuli were applied to the periphery of the body. Confirming all these discoveries was adauced the evidence derived from the results of localised extirpation of the cortex. The lecturer criticised adversely Luciani's view, reaching the opposite extreme to tha's of Goltz, that there was "a centre of centres" near the face area in which a maximum of overlapping occurred, and by the stimulation of which the greatest spread of effect was produced. Summarising the evidence derived both from paralysing and excitation experiments, he maintained that it all went to prove the existence of centres in the cortex, and any evidence which was apparently adverse depended on the neglect of certain necessary precautions of experiment.

The Function of the Cortical Centres.

The second point-the precise function of these centres-was next discussed. He pointed out that extirpation of emall areas of the cortex in dogs did not produce actual paralysis, as in man, but only a condition in which the animals used their limbs in unsuitable ways, and did not correct unsuitable positions into which the limbs were passively placed, showing that they had lost the complete consciousness of the condition of their limbs.

Are the Cortical Centres Motor or Sensory or both ?

Subsequent knowledge had led to the formation of two main theories in explanation of these results, the motor theory and the sensory theory. While Ferrier had maintained that in apes the results of extirpation of the central convolutions of the cortex were purely motor, in which view he had more recently been supported by Schäfer, who found that the animals "still felt the slightest touch of a straw," Munk, Mott, and Bechterew had maintained that sensory changes were also present.

In regard to the dog to which Ferrier had extended the observation made on the ape, Professor Hitzig said that in his opinion it could not be doubted that any lesion of the motor cortex was "glways and without exception combined with disturbances which affect the sensibility of the whole limbthat is to say, of the skin, of the muscles, of the joints. etc.," and he himself would extend the same observation from 8 mere process of reasoning apart from experiment to the ape. 
On the other hand, he accepted Schäfer's conclusion that " the motor paralysis could not possibly be based on a totally imperceptible sensory disturbance."

He next adversely criticised Schiff's views that the motor paralysis was due to cutting off of sensation from the ekin, and Munk's view that the cortical centres were purely motor. Professor Hitzig himself attributed the paralysis to defects in the cortical centres induced by " disturbances of the consciousness of the limbs," or, as he enunciated his doctrine in regard to the dog," that in the extremity regions only the conscious working over of all the feelings that arise subcortically to more or less well localised conceptions of feeling takes place." But he attributed the cause of the so-called voluntary movements in only a small proportion of cases to those conceptions of motions alone; in the majority of cases there was in addition as a factor in producing the movement the intervention of an excitement of the senses, as of sight, or of an "intellectual occurrence in order to disengage the conception of movement, and therewith the act of motion."

Whence the Contradiction in Regard to the Function OF THE Cortex?

The differences in opinion in respect of the functions of the cortex depended, Professor Hitzig believed, on two facts that different investigators had extended their conclusions ton widely, without sufficiently regarding the anatomical and physiological differences of the brains of different species, and the difficulty arising from the fact that functions lost after lesions really or apparently returned. In attempting to dispose of these difficulties he pointed out that the motor disturbances produced in the dog by lesions of the cortex might be divided into three groups-the taking up of abnormal positions by the limbs; the behaviour of the dog in stepping with its affected forepaw blindly into the air, for example from a table, even although sight was unaffected; and the paralysis of isolated intentional motion. He accepted as a valuable term the kinæsthesis of Bastian, or the storing up of the sensory impressions associated with movement, but he held a still wider view in that the conceptions of feeling obtained from the painless handling of the skin came into play, and these he considered did not directly belong to the kinæsthetic impressions or sensations of movement, although closely related to them. In referring to the paralysis of isolated intentional motion, such as that of an ape, in which what was known as the hand centre had been excised, although it could run and climb, it could not purposely grasp a fig with the paralysed hand and put it to its mouth, or, as described by Goltz, dogs who had learned tricks lost after the operation the power to give the paw. The lecturer summarised his conclusions as follows: "In all these cases we see that the further conceptions of the animal, the total of which we are accustomed to call his will, in whatever field of the senses they may have arisen, are no longer in a position to excite the motions that are necessary to the carrying out of the will, the moment that the centre $I$ have named is extirpated for the fore-limb."

Reration of Motor Centres to other Corticat Centres.

The lecturer then proceeded to discuss the relation of the motor region of the cortex to the faculty of sight, criticising Goltz s view that it was as much represented in the anterior part of the brain as in the posterior or occipital part ; whether, in fact, there were two centres for sight, or one alone. He adduced evidence to show that the disturbance of vision which arose after lesions in the motor zone were only indirectly dependent upon this zone, that the latter did not serve for vision, and that, in consequence, the disturbance of vision could only be based upon a process of inhibition that was passed on into the centres of vision.

\section{The Differences in the Brain Cortex of Different} Sprcirs.

He explained the differences in the effect of lesions of the cortex in the dog as compared with the apes and man on the ground that with the progressive development of the individual what were originally subcortical centres became pushed up into the cortical sphere of consciousness, and as consciousness was developed these centres became more widely separated, and took up more complex associations.
The Difficulty of the Restitution of Function.

In explanation of the second difficulty, that of the apparent restoration of functions which bad been apparently lost, he distinguished between two sets of motor centres, a lower subcortical or reflex set and a higher or cortical set concerned with "conscious arbitrary motion." The experiments of Schäfer, Munk, and others had taught "in what way motor impulses from other than the motor regions of the brain cortex of the animal can become effectual ; they have shown that conjugated eye and head motions occur upon excitation of the occipital lobe-that is to say, motions that are to be paralleled with the locomotor associated motions of the animals. From this alone it was then to be concluded that such associated motions were not started merely by the motor region, but also from large districts of the brain cortex."

Other experiments had shown that these subcortical centres and the courses of communication that radiate from them were dominated by the cortical centres, and the restoration of function corresponded with an accommodation to the new conditions, and " at the same time a breaking up of the way upon still existing courses of communication."

\section{Some Personal Considerations.}

The lecturer, in concluding, spoke as follows: "If we now, according to the task set us, compare the standpoint of science to-day with the theories that Hughlings Jackson set up thirty years ago, we find, as must be expected from the defects attaching to human research, that some of his views have as a whole or in single parts needed to be corrected, while doubt to-day still reigns as to others, but that the most essential of them have found a brilliant confirmation at the hands of physiological research, to say nothing of clinical and anatomical research. If we turn our eyes from that which will gradually pass into forgetfulness, we must in the first place emphasise. as an indelible leaf in the history of medicine, Jackson's doctrine of the cortical convulsions, both the general principle of the charging and of the discharge that makes inroads on the neighbouring domains, and the numerous details by which this principle was explained and firmly grounded; in it especially the part determining the muscles in which the cortical fit begins and the sequence in which they are affected by the fitg after different beginnings.........Taking it all in all, we see, even in the part of Dr. Jackson's scientific work that I have described, the work of a man of whom any nation may rightly be proud.........We, too, we labourers in the realm of the natural sciences, to whatever nation we belong, are soldiers and form an army, but an army that knows of no separation into different camps as a result of national or other interests, an army that is united in the one interest, in the search after truth, in the battle against ignorance and against all the hindrances which some men would like to oppose to our endeavour to reach our ideal aims. It may count as an expression of the mutual character of our cause, that I as a foreigner was called to-day to do honour to a scholar of this country, and for this reason also I have discharged this flattering task with joy and pride."

Tobarculosis and Quaranmink.-The United States Commissioner of Immigration has decided that tuberculosis is a disease which may subject the patient to quarantine. A Japanese with tuberculosis arrived at San Francisco, and it was decided that the patient could not land, and must return to the port from which he sailed.

The Hancox Home for Male Inebriates. - The Committee of the Church of England Temperance Society having appointed a superintendent who took charge of this home on November 5 th, the first patients were received on November 8th. It is stated that the Committee still need about $£ 300$ to place the home in a satisfactory financial condition.

Notification of Phthisis in Germany.-Cases of pulmonary and laryngeal tuberculosis which have reached the stage of cachexia are made notifiable by a recent decree of the Minister of the Interior in Saxony. The notification is compulsory only if the patient moves from one plare to another, or has become dangerous to those about him. Cases of the kind treated in private institutions or lodged in hotels or boarding houses must also be notified. 